\title{
Влияние человеческого капитала на результативность новых предпринимательских команд: обзор эмпирических исследований
}

\section{Никита Кадиров}

Дальневосточный федеральный университет, г. Владивосток, Россия

\author{
Информация о статье \\ Поступила в редакцию: \\ 08.04 .2020 \\ Принята \\ к опубликованию: \\ 02.06.2020
}

УДК $331.103 ; 331.44$

JEL M13

\section{Ключевые слова:}

предпринимательство, человеческий капитал, новое предприятие, новая предпринимательская команда

\section{Keywords:}

entrepreneurship, human capital, new venture, venture team

\begin{abstract}
Аннотация
Настоящиий обзор литературы посвящён вопросу влияния человеческого капитала на результативность новых предпринимательских команд. Было проанализировано 18 эмпирических исследований, опубликованных в период с 1995 по 2019 ге. Цель работы - систематизировать и обобщчить результаты этих исследований, так как они неоднозначны и противоречивы. В результате исследования сделан вывод о том, что прирост человеческого капитала в новой предпринимательской команде приводит к росту результативности, только если он соответствует стратегии и целям предприятия, является комплементарным и актуальным.
\end{abstract}

\section{Human Capital Impact on the New Venture Teams \\ Performance: a Review of the Empirical Research}

Nikita Kadirov

\begin{abstract}
Entrepreneurship has never been so important for economic growth as it is in the modern open economy. Demand for entrepreneurs with their ability to innovate and compete has been increasing since the 1980 s due to the structural changes in the economy triggered by globalization and ICT-revolution. Today new firms with high growth potential have a significant impact on the economic growth. Many factors determine the growth and performance of new ventures. This literature review focuses on the human capital of new venture teams. It's based on the analysis of 18 empirical researches published between 1995 and 2019. The objective of the review is to systematize and summarize their results, as they are sometimes ambiguous and contradictory. The main conclusion is that human capital in a new venture team leads to the increased performance only if it meets three criteria.

Firstly, human capital should be goal-oriented, i.e. be consistent with strategy and goals. Secondly, sometimes human capital is excessive and contains irrelevant or outdated experience, skills,
\end{abstract}


and knowledge so it should be nonredundant. Finally, the positive impact of human capital on the new venture team performance is observed when complementary skills, knowledge, and experience are combined in a team. So human capital should be diverse and complementary. The article concludes with recommendations for new venture teams based on three previously described criteria.

\section{Введение}

Предприниматели редко действуют без партнеров, а мифы об «одиноком лидере» и «одиноком гении» не имеют ничего общего с реальностью $[1,2]$. По статистики новые предприятия в большинстве случаев основываются командами, которые, как правило, могут называться «стартап-команды», «команды основателей» «новые предпринимательские команды» и пр. [3, 4, 5, 6, 7].

По данным до $40 \%$ новых предприятий проваливаются в первый год работы $[8,9]$. При этом от 60 до $65 \%$ неудачных проектов проваливаются изза низкой результативности новой предпринимательской команды (далее НПК), о чём свидетельствуют опросы инвесторов и анализ инвестиционных портфелей венчурных фондов $[10,11]$. Венчурные инвесторы рассказывают, что топ-менеджеров часто приходится увольнять, потому что они не справляются, а слабый топ-менеджмент - основная причина, из-за которой компании теряют инвестиции и закрываются [10].

В то же время, человеческий капитал, в том числе образование, опыт, знания и навыки традиционно рассматривается как важный ресурс для успеха предпринимательских фирм, поскольку он, по утверждению разных авторов, (1) улучшает способность к обнаружению и использованию предпринимательских возможностей, (2) положительно влияет на умение планировать и формировать стратегию и (3) помогает находить необходимые ресурсы, в том числе финансовые [12].

Возникает вопрос: действительно ли человеческий капитал новой предпринимательской команды влияет на её результативность? Если влияет, то каким образом? Проведено немало эмпирических исследований, которые по-разному отвечают на этот вопрос, при этом многие ответы неоднозначны. В работе проанализированы результаты существующих исследований, на основании которых и был подготовлен данный обзор. Основная цель заключается в систематизации и обобщении результатов исследований, рассматривающих влияние человеческого капитала новой предпринимательской команды на её результативность. Объектом являются статьи по указанной теме в рецензируемых научных журналах, а предметом - результаты описанных в статьях исследований, характеризующие природу взаимосвязи между человеческим капиталом и результативностью новой предпринимательской команды. Для достижения поставленной цели необходимо решить несколько задач: (1) описать ключевые для обзора теоретические концепции; (2) отобрать научные статьи для обзора; (3) систематизировать статьи исходя из подхода к оценке человеческого капитала и (4) проанализировать статьи и обобщить результаты.

Работа состоит из четырёх разделов и заключения. В первом разделе описаны концепции «новая предпринимательская команда» и «человеческий капитал», которые являются ключевыми для обзора. Во втором разделе пред- 
ставлен процесс поиска и отбора исследований для анализа. Третья часть рассматривает подходы авторов к оценке человеческого капитала и результативности НПК. В заключительном разделе приведены результаты анализа и систематизации исследований, отобранных для обзора.

\section{Теория}

Кониепция новой предпринимательской команды. Чтобы иметь возможность в полной мере обсудить понятие «новая предпринимательская команда», необходимо предварительно дать определение понятию «новое предприятие» (new venture) и показать, что под ним подразумевают исследователи предпринимательства. Из словарей английского языка Merriam-Webster и Collins можно узнать, что слово «предприятие» (venture) означает некоторое начинание, связанное с риском, которое обычно заключается в создание бизнеса. Но какое предприятие можно считать новым? Созданное несколько месяцев или несколько лет назад? Привлекающее самых первых клиентов или перешедшее от стадии становления к стадии активного роста? Научная дискуссия по этому вопросу продолжается. На сегодняшний день в ней сформировалось, как минимум, два подхода, каждый из которых позволяет посвоему ответить на поставленные вопросы.

Представители первого подхода, сформированного в первой половине 1990-х гг., в качестве критерия новизны предприятия используют его возраст. Такого мнения придерживаются Д. Ковин и Д. Слевин в работе о стратегиях новых предприятий [13], П. Рейнольдс и Б. Миллер [14], а также К. Браш [15]. Этот подход предлагает точный и практичный критерий для определения того, какое предприятие можно считать новым. Но в это же время, как нижнее, так и верхнее пороговое значение этого критерия варьируется от исследования к исследованию в промежутке от 6 до 10 лет.

Э. Клотз и соавторы предлагают определить новое предприятие более широко, как организацию, которая находится на ранних стадиях своего развития и роста [5]. С этой точки зрения предприятие можно считать новым, если оно находится в процессе вывода продукта на рынок, формирования клиентской базы и упорядочивания бизнес-процессов. Хотя Э. Клотз и соавторы не уточняют, какие именно стадии развития и роста следует считать «ранними», их определение, тем не менее, указывает на логику, которой следует руководствоваться, чтобы отличить новое предприятие от зрелого.

Для обозначения команд, возглавляющих новые предприятия, обычно используют понятие «новая предпринимательская команда» (new venture teams), то есть «группа людей, несущая ответственность за принятие стратегических решений и операционную деятельность нового предприятия» [5]. В ранних определениях этого термина подчеркивалось, что члены новой предпринимательской команды должны быть финансово заинтересованы в успехе нового предприятия, например, владеть некоторой его частью, но со временем от этого критерия отказались, потому что из-за него в команду не попадают наёмные топ-менеджеры, чей финансовый интерес ограничивается заработной платой и бонусами [5].

Конщепџия человеческого капитала. Согласно классическому определению Т. Шульца, человеческий капитал представляет собой знания и навыки, 
которые люди приобретают в результате обучения, образовательных мероприятий на работе или из любых других источников опыта [16]. Такого же определения придерживался и Г. Беккер, популяризировавший понятие «человеческий капитал». В более поздних концепциях к знаниям и навыкам добавились другие черты личности, такие как умение обучаться, воображение, креативность и мотивация $[17,18]$. Г. Беккер предложил две, основанные на противопоставлении, концептуализации проявлений человеческого капитала: инвестиции в человеческий капитал (образование, опыт работы) и результаты инвестиций в человеческий капитал (знания и навыки), а также человеческий капитал, связанный с задачами, и человеческий капитал, не связанный с задачами.

\section{Поиск и отбор исследований}

Для исследования были отобраны научные статьи, опубликованные в период с 1995 по ноябрь 2019 гг. Для поиска статей использовалась библиографическая база данных Scopus. Отбор эмпирических исследований для обзора проходил в три этапа.

Во-первых, мы получили из базы данных все публикации, в заголовках, аннотациях и ключевых словах которых упоминались новые предпринимательские команды. По аналогии с подходом Э. Клотза и соавторов [19] для поиска мы использовали несколько взаимозаменяемых ключевых фраз для обозначения новой предпринимательской команды: (1) «new venture team», (2) «start-up team» и (3) «founding team». По сформированному запросу было найдено 896 статей.

Во-вторых, мы проанализировали названия найденных статей на предмет упоминания эффективности, результативности или других терминов, близких к ним по значению - в результате выборка сократилась до 150 статей. После этого мы аналогичным образом рассмотрели аннотации и сократили её до 77 публикаций.

В-третьих, мы ознакомились с полным текстом работ из полученной выборки и составили структурированное краткое описание для каждого исследования. Человеческий капитал рассматривается как фактор результативности новой предпринимательской команды в 18 работах - эти публикации и составляют выборку настоящего обзора.

\section{Человеческий капитал в исследованиях результативности новых предпринимательских команд}

Человеческий капитал, в том числе образование, опыт, знания и навыки, традиционно рассматривается как важный ресурс для достижения предпринимательского успеха [19]. В литературе о предпринимательстве представлено множество аргументов в пользу утверждения о том, что человеческий капитал ведёт к предпринимательскому успеху: повышает способность к поиску и использованию предпринимательских возможностей, к планированию и разработке стратегии и, кроме того, является предпосылкой к дальнейшему обучению и накоплению полезных знаний и навыков [19].

В исследованиях, посвящённых влиянию человеческого капитала на результативность НПК, объём человеческого капитала оценивается поразному: в основном ученые используют в качестве независимой переменной 
количество лет определённого опыта (функционального, отраслевого, предпринимательского, управленческого и т.д.) или уровень образования. В большинстве исследований авторы комбинируют несколько подходов. В табл. 1 приведены соответствующие данные по всем исследования, которые обсуждаются в этом обзоре.

Таблица 1

\section{Подходы исследователей к оценке человеческого капитала и результативности новых предпринимательских команд}

\begin{tabular}{|c|c|c|}
\hline Исследование & $\begin{array}{c}\text { Подход к оценке человеческого } \\
\text { капитала }\end{array}$ & Подход к оценке результативности \\
\hline McGee et al., 1995 & Функциональный опыт и навыки & Темпы роста продаж за 3 года \\
\hline Colombo \& Grilli, 2005 & $\begin{array}{l}\text { Отраслевой опыт, } \\
\text { предпринимательский опыт, } \\
\text { управленческий опыт, } \\
\text { образование }\end{array}$ & Численность персонала \\
\hline Shrader \& Siegel, 2007 & $\begin{array}{l}\text { Функциональный опыт и навыки, } \\
\text { отраслевой опыт, } \\
\text { предпринимательский опыт, } \\
\text { опыт международной деятельности }\end{array}$ & $\begin{array}{l}\text { ROI, ROS, ROA и темпы роста продаж за } \\
10 \text { лет после IPO }\end{array}$ \\
\hline Dahl \& Reichstein, 2007 & $\begin{array}{l}\text { Отраслевой опыт, } \\
\text { предпринимательский опыт, } \\
\text { образование }\end{array}$ & Выживание \\
\hline Colombo \& Grilli, 2007 & $\begin{array}{l}\text { Отраслевой опыт, } \\
\text { управленческий опыт, } \\
\text { предпринимательский опыт, } \\
\text { образование }\end{array}$ & Численность персонала \\
\hline $\begin{array}{l}\text { Leary \& DeVaughn, } \\
2009\end{array}$ & $\begin{array}{l}\text { Отраслевой опыт, } \\
\text { предпринимательский опыт, } \\
\text { опыт совместной работ }\end{array}$ & Получение банковской лицензии \\
\hline Patzelt, 2010 & $\begin{array}{l}\text { Отраслевой опыт, } \\
\text { опыт международной деятельности, } \\
\text { образование }\end{array}$ & Получение венчурного финансирования \\
\hline Gurau et al., 2010 & $\begin{array}{l}\text { Функциональный опыт и навыки, } \\
\text { управленческий опыт, } \\
\text { предпринимательский опыт }\end{array}$ & $\begin{array}{l}\text { Число патентов и запущенных проектов и } \\
\text { доход }\end{array}$ \\
\hline Brinckmann et al., 2011 & Функциональный опыт и навыки & Рост продаж и численность персонала \\
\hline Ganotakis, 2012 & $\begin{array}{l}\text { Отраслевой опыт, } \\
\text { функциональный опыт и навыки, } \\
\text { управленческий опыт, } \\
\text { образование }\end{array}$ & Численность персонала \\
\hline Zheng, 2012 & Опыт совместной работы & $\begin{array}{l}\text { Шкала на основе работ Chandler (1996) и } \\
\text { Eisenhardt \& Schoonhoven (1990) }\end{array}$ \\
\hline Zhao et al., 2013 & $\begin{array}{l}\text { Функциональный опыт и навыки, } \\
\text { предпринимательские возможности }\end{array}$ & Прибыль \\
\hline Visintin \& Pittino, 2014 & Опыт совместной работы & $\begin{array}{l}\text { Темпы роста продаж и численности персо- } \\
\text { нала за } 3 \text { года }\end{array}$ \\
\hline De Cleyn et al., 2015 & $\begin{array}{l}\text { Функциональный опыт и навыки, } \\
\text { предпринимательский опыт }\end{array}$ & $\begin{array}{l}\text { Ежегодные данные о ЕВIT и обороте, } \\
\text { численность персонала и выживание }\end{array}$ \\
\hline Huynh et al., 2017 & $\begin{array}{l}\text { Отраслевой опыт, } \\
\text { предпринимательский опыт, } \\
\text { предпринимательские возможности }\end{array}$ & $\begin{array}{l}\text { Темпы роста продаж, дохода и чистой } \\
\text { прибыли }\end{array}$ \\
\hline Protogerou et al., 2017 & $\begin{array}{l}\text { Отраслевой опыт, } \\
\text { функциональный опыт и навыки, } \\
\text { образование }\end{array}$ & $\begin{array}{l}\text { Доля расходов на НИОКР, уровень ради- } \\
\text { кальности инноваций }\end{array}$ \\
\hline Shu \& Simmons, 2018 & Отраслевой опыт & Выживание \\
\hline Ko \& McKelvie, 2018 & $\begin{array}{l}\text { Отраслевой опыт, } \\
\text { образование, } \\
\text { предпринимательский опыт }\end{array}$ & Объём венчурного финансирования \\
\hline
\end{tabular}

Источник: составлено автором 


\section{Роль человеческого капитала в зависимости от подхода к его оценке}

Отраслевой onыm. В большинстве исследований для оценки человеческого капитала использовался отраслевой опыт, то есть время, которое члены НПК работали или стажировались в компаниях из той же отрасли, в которой работает предприятие, которым они управляют.

М. Коломбо и Л. Грилли провели два исследования, в которых изучали связь между отраслевым опытом команды и ростом предприятия (оценивался как прирост числа постоянных сотрудников) на примере НПК молодых технологических компаний из Италии $[20,21]$. Выяснилось, что отраслевой опыт технического характера способствует достижению впечатляющего роста, что неудивительно для выборки из технологических компаний [20]. Кроме того, результаты исследования показали, что управленческий опыт также положительно влияет на рост и увеличивает шансы на получение внешнего финансирования. Максимальные темпы роста были зафиксированы в компаниях, где члены НПК одновременно обладали коммерческим опытом и отраслевым опытом технического характера. В исследовании подтверждаются идеи компетентностного подхода (competence-based view), о том, что конкурентные преимущества нового предприятия тесно связаны со знаниями и навыками его основателей [22], и «знаниевого» подхода (knowledge-based view), согласно которому именно специальные знания является основой конкурентных преимуществ.

Р. Шрейдер и Д. Сигел на примере молодых технологических компаний (не старше 6 лет) показали, что ни отраслевой, ни предпринимательский, ни международный опыт сами по себе не оказывают существенного влияния на темпы роста продаж и рентабельность нового предприятия [23]. Влияние становится заметным, если опыт команды совпадает с конкурентной стратегией предприятия [23]:

-предпринимательский опыт полезен при реализации стратегий, связанных с быстрым ростом (много покупателей, сегментов рынка или продуктов) и помогает добиться роста продаж;

-опыт международной деятельности помогает увеличить рентабельность и добиться роста продаж в компаниях с большой долей трансграничных продаж;

-отраслевой опыт помогает увеличить рентабельность и добиться роста продаж при реализации стратегии экономии на издержках;

-технический опыт, напротив, снижает продажи и рентабельность при реализации агрессивных стратегий (увеличение доли рынка, захват позиций на рынке), потому что, как считают авторы, предприниматели с техническим складом ума склонны излишне оптимистично оценивать рыночный потенциал своей технологии [23].

М. Дал и Т. Рейхштайн исследовали как на «выживание» спин-оффов влияет отраслевой и предпринимательский опыт и статус родительской организации. Авторы не обнаружили существенного влияния опыта «выживание». При этом наличие успешно функционирующей родительской организации закономерно увеличивает шансы спин-оффа закрепиться на рынке [9]. 
Ч. Шу и Ш. Симмонс провели аналогичное исследование, но на примере обычных новых предприятий, а не спин-оффов. Результаты, в отличии от работы М. Дала и Т. Рейхштайна, показывают, что отраслевой опыт положительно влияет на «выживание» нового предприятия. Однако его влияние может быть подавлено эффектом локализации, то есть в случаях высокой концентрации предприятий из одной отрасли на одной территории [24].

Ещё один неоднозначный результат получили исследователи из США, М. Лири и М. ДеВон [Leary and DeVaughn, 2009]. Они выяснили, что у НПК с меньшим объемом отраслевого опыта больше шансов успешно запустить новое предприятие. Исследование проводилось среди новых организаций, претендовавших на получение банковской лицензии в США, получение которой и считалось успешных запуском. В среднем по выборке команда основателей имела 74 года отраслевого опыта [Leary and DeVaughn, 2009]. По мнению авторов, внушительный объем опыта не всегда полезен, так как большая его часть была получена давно и уже устарела. Тем не менее, члены НПК будут обращаться к нерелевантному опыту в силу привычки, поэтому во многих ситуациях НПК с меньшим объёмом отраслевого опыта могут действовать эффективнее.

Из этого следует, что зависимость между опытом и результативностью может иметь U-образный характер, то есть полезность опыта начинает убывать после того, как его объём достигает определённого значения. Это подтвердилось в работе П. Ганотакиса, который предположил, что убывающая полезность опыта может быть следствием излишней самоуверенности наиболее опытных предпринимателей и нежелания полагаться на чью-то помощь или советы [25]. Также он показал, что человеческий капитал в целом и отраслевой опыт в частности положительно влияют на рост числа постоянных сотрудников компании. Вывод Ганотакиса напоминает работы М. Коломбо и Л. Грилли $[20,21]$ и заключается в том, что не отдельный вид опыта увеличивает результативность НПК, а удачная комбинация управленческих навыков технического и коммерческого характера. Несмотря на то, что конкурентные преимущества технологической компании в соответствии с компетентностным подходом в первую очередь зависят от технической экспертизы НПК, на практике они могут оказаться бесполезны без навыков эффективной работы с рынком.

Ещё одно аналогичное исследование опубликовал в 2017 г. Т. Хейн с соавторами [26]. В нём на примере университетских спин-оффов из Испании было показано, что отраслевой опыт никак не влияет на финансовую и операционную эффективность или даже влияет отрицательно. Авторы объясняют это тем, что впечатляющим опытом обладают предприниматели в возрасте, а их гордость и самоуверенность сдерживают мотивацию к поиску новых решений, к своевременной реакции на динамику рынка.

На примере 117 случаев финансирования новых биофармацевтических компаний Х. Патцельт выяснил, что отраслевой опыт в большинстве случаев не влияет на шансы получить финансирование, как и опыт международной деятельности [27]. Однако, если по отдельности рассмотреть случаи с небольшими и крупными НПК, оказывается, что для небольших НПК влияние отраслевого опыта на шансы получить финансирование будет положительным, а для крупных - отрицательным [27]. 
В исследовании А. Протогеру с соавторами на выборке из молодых европейских компаний было показано, что объём отраслевого опыта положительно влияет на интенсивность НИОКР [28]. А если у членов НПК есть опыт организации или участия в такой работе, то это положительно влияет на интенсивность НИОКР и уровень радикальности инноваций. Кроме того, вероятность достичь высокого уровня радикальности инноваций выше для предприятий, у которых в команде есть разнообразный, но комплементарный человеческий капитал, например, технологические и маркетинговые навыки одновременно.

Функциональный опыт, навыки и компетенциии. Второй по популярности способ оценки человеческого капитала - количество лет функционального опыта, то есть то время, которое члены НПК занимались определённой профессиональной деятельностью.

Д. МакГи с соавторами ещё в 1995 г. опубликовали исследование, в котором рассматривалась роль опыта членов НПК в производстве, маркетинге и НИОКР. Результаты исследования показали, что наличие опыта, подходящего для реализации выбранной кооперативной стратегии, положительно влияет на продажи [29].

Я. Бринкманн и соавторы изучили НПК молодых технологических компаний из Германии и выяснили, что компетенции в стратегическом и финансовом менеджменте положительно влияют на темпы роста продаж и найма сотрудников [30].

В исследовании Л. Чжао с соавторами рассматривается, как навыки и знания в области маркетинга и сервисного дизайна влияют на результативность компании напрямую и через формирование стратегических позиционных преимуществ (защищенности и масштабируемости). Результаты показали, что знания и навыки в маркетинге положительно влияют на результативность и способствуют лучшей масштабируемости. А навыки сервисного дизайна увеличивают уровень масштабируемости и защищенности [31].

С. Де Клейн с соавторами изучали академические спиноффы из Европы и показали, что комплементарный функциональный опыт НПК положительно влияет на успешность нового предприятия, а предпринимательский опыт, напротив, не оказывает никакого влияния [32]. В частности, ожидаемый положительный эффект от наличия серийных предпринимателей в составе НПК на практике оказался негативным, из-за влияния предпринимательской эйфории и чрезмерной уверенности. К аналогичным выводам пришла А. Протогеру, рассказавшая о том, что комплементарный функциональный опыт в технологиях и маркетинге положительно влияет на инновационную эффективность, в частности на радикальность инноваций и интенсивность НИОКР [28].

Как и в случае с отраслевым, функциональный опыт положительно влияет на результативность НПК при соблюдении некоторых условий: (1) соответствие функционального опыта кооперативной или конкурентной стратегии, а также (2) комплементарность функционального опыта. Проанализированные исследования показывают, что команды, в которых функциональный опыт сосредоточен в одной сфере деятельности, наиболее уязвимы, поскольку могут сформировать только одно сильное конкурентное преиму- 
щество, которое само по себе бесполезно для роста и недостаточно для защиты от конкурентов.

Образование. Ещё один популярный способ оценки человеческого капитала - образование, для которого оценивается как объём, то есть то время, которое члены НПК потратили на обучение, так и уровень, то есть степень, которую они имеют по итогам обучения.

Уже упомянутые исследования М. Коломбо и Л. Грилли показали, что объем образования на темпы роста нового предприятия не влияет. Но влияет уровень и специальность: наличие степени в экономике или менеджменте и, в меньшей степени, в технических науках положительно влияет на темпы роста нового предприятия. Это говорит о том, что даже в технологических компаниях развитие в большей степени зависит от знаний и навыков, связанных с ведением бизнеса. Однако в исследовании Х. Патцельта, выяснилось, что управленческое образование влияет положительно только на результативность крупных НПК, поэтому вероятно, что закономерность, выявленная М. Коломбо и Л. Грилли работает не во всех случаях [27].

М. Дал и Т. Рейхштайн выделили три уровня образования: 1 - уровень окончания старшей школы, 2 - степень бакалавра, 3 - степень магистра или выше [33]. Выяснилось, что чем выше средний уровень образования в НПК, тем выше шансы нового предприятия на выживание. А. Протогеру с соавторами в своём исследовании аналогичным образом оценивала образование и показала, что оно положительно влияет на интенсивность НИОКР и радикальность инноваций. Также выяснилось, что средний уровень образования положительно влияет на объём венчурного финансирования в 1 и 2 инвестиционных раундах [33].

Судя по результатам исследований, не объём, а специфика образования в большей степени определяет результативность НПК. Однако есть исключение - инновационная эффективность, поскольку навыками НИОКР, как правило, обладают руководители с высоким уровнем образования.

\section{Заключение}

Итак, что нам известно о влиянии человеческого капитала на результативность новых предпринимательских команд? Судя по результатам эмпирических исследований, человеческий капитал действительно способствует предпринимательскому успеху, но для этого он должен соответствовать трём критериям: (1) целенаправленность, (2) неизбыточность и (3) комплементарность.

Во-первых, большой объём человеческого капитала не гарантирует высокую результативность НПК. Каждый раз, когда исследователи пытались проверить такую гипотезу, они сталкивались с тем, что она работает только в определённом контексте. Поэтому человеческий капитал, как и инвестиции, следует рассматривать как целевой. Если вы потратили на обустройство офиса инвестиции, выделенные на совершенствование продукта, рассчитывать на успех и удовлетворённость инвесторов не приходится. Это справедливо и для человеческого капитала: независимо от объёма, он не обеспечивает прирост результативности, если используется не по назначению. Человеческий капитал должен соответствовать стратегии, целям и задачам предприятия. 
Во-вторых, человеческий капитал может быть излишним - в особенности это касается опыта. Так как большой объём опыта обычно приобретается в течение длительного промежутка времени, часть из него может быть неактуальной, «устаревшей», особенно в наиболее динамичных отраслях экономики. Если участники НПК будут использовать такой опыт при принятии решений, с высокой долей вероятности решения будут неправильными.

Наконец, положительное влияние человеческого капитала на результативность НПК наблюдается, когда в команде объединены комплементарные навыки, знаний и опыт. Например, команда, участники которой обладают превосходной экспертизой в области технологий, не может рассчитывать на коммерческий успех, если в ней нет компетентного маркетолога или менеджера по продажам. Для развития предприятия недостаточно даже первоклассной экспертизы в единственной области. Чтобы человеческий капитал оказывал максимальное положительное влияние на результативность НПК, он должен быть разнообразным и комплементарным.

Основываясь на трёх критериях, которые, как показывает наш анализ литературы, позволяют максимизировать полезность человеческого капитала, можно сформулировать несколько практических рекомендаций для новых предпринимательских команд. В первую очередь команда должна определиться с тем, какие навыки и знания являются критически важными для развития предприятия. Если члены команды в совокупности обладают всеми необходимыми знаниями и навыками, можно сказать, что человеческий капитал предпринимательской команды отвечает критериям целенаправленности и комплементарности. Если какие-то из критических знаний и навыков не представлены в команде, это следует исправить с помощью обучения или привлечение дополнительных партнёров. Кроме того, для достижения неизбыточности человеческого капитала, необходимо привлекать к работе экспертом с разным объёмом опыта. Нет необходимости, чтобы все эксперты были частью новой предпринимательской команды - они могут быть сотрудниками или консультантами. Но, как показывают результаты исследований, устойчивый и быстрый рост наблюдается в тех компаниях, где взвешенное экспертное мнение, основанное на глубоком опыте, сопровождается критикой, основанной на свежем, лишённом стереотипов взгляде на проблему.

\section{Список источников / References}

1. Carland J.A.C., Carland Jr J.W. A model of shared entrepreneurial leadership. Academy of Entrepreneurship Journal, 2012, vol. 18, no. 2, pp. 71-82.

2. Hill L.A. et al. Collective genius: The art and practice of leading innovation. Harvard Business Review Press, 2014.

3. Cooper A.C., Woo C.Y., Dunkelberg W.C. Entrepreneurship and the initial size of firms. Journal of Business Venturing, 1989, vol. 4, vol. 5, pp. 317-332.

4. Kamm J.B. et al. Entrepreneurial teams in new venture creation: A research agenda. Entrepreneurship theory and practice, 1990, vol. 14, no. 4, pp. 7-17.

5. Klotz A.C. et al. New venture teams: A review of the literature and roadmap for future research. Journal of management, 2014, vol. 40, no. 1, pp. 226-255.

6. Reynolds P.D., White S.B. The entrepreneurial process: Economic growth, men, women, and minorities. Praeger Pub Text, 1997. 
7. West III G.P. Collective cognition: When entrepreneurial teams, not individuals, make decisions. Entrepreneurship Theory and Practice, 2007, vol. 31, no. 1, pp. 77-102.

8. Timmons J.A. New venture creation: Entrepreneurship in the 1990s. Irwin Professional Publishing, 1990.

9. Dimov D., De Clercq D. Venture capital investment strategy and portfolio failure rate: A longitudinal study. Entrepreneurship Theory and Practice, 2006, vol. 30, no. 2, pp. 207-223.

10. Gorman M., Sahlman W.A. What do venture capitalists do? Journal of business venturing, 1989, vol. 4, no. 4, pp. 231-248.

11. Kaplan S.N., Strömberg P.E.R. Characteristics, contracts, and actions: Evidence from venture capitalist analyses. The Journal of Finance, 2004, vol. 59, no. 5, pp. 2177-2210.

12. Unger J.M. et al. Human capital and entrepreneurial success: A meta-analytical review. Journal of business venturing, 2011, vol. 26, no. 3, pp. 341-358.

13. Covin J.G., Slevin D.P. New venture strategic posture, structure, and performance: An industry life cycle analysis. Journal of business venturing, 1990, vol. 5, no. 2, pp. 123-135.

14. Reynolds P., Miller B. New firm gestation: Conception, birth, and implications for research. Journal of business venturing, 1992, vol. 7, no. 5, pp. 405-417.

15. Brush C., International Entrepreneurship: The Effect of Firm Age on Motives for Internationalization. Garland Publishing, London, 1995.

16. Schultz T.W. Investment in human capital. The American economic review, 1961, vol. 51 , no. 1 , pp. 1-17.

17. Psacharopoulos G., Woodhall M. Education for Development: An Analysis of Investment Choices (Washington, DC: World Bank), 1985.

18. Fitz-Enz J. The ROI of human capital: Measuring the economic value of employee performance. AMACOM Div American Mgmt Assn, 2000.

19. Unger J.M. et al. Human capital and entrepreneurial success: A meta-analytical review. Journal of business venturing, 2011, vol. 26, no. 3, pp. 341-358.

20. Colombo M.G., Grilli L. Founders' human capital and the growth of new technologybased firms: A competence-based view. Research policy, 2005, vol. 34, no. 6, pp. 795-816.

21. Colombo M.G., Grilli L. Funding gaps? Access to bank loans by high-tech start-ups. Small Business Economics, 2007, vol. 29, no. 1-2, pp. 25-46.

22. Cooper A.C., Bruno A.V. Success among high-technology firms. Business horizons, 1977, vol. 20, no. 2, pp. 16-22.

23. Shrader R., Siegel D.S. Assessing the relationship between human capital and firm performance: Evidence from technology-based new ventures. Entrepreneurship theory and Practice, 2007, vol. 31, no. 6, pp. 893-908.

24. Shu C., Simmons S.A. Firm survival in traded industries: does localization moderate the effects of founding team experience? Small Business Economics, 2018, vol. 50, no. 3, pp. 643-655.

25. Ganotakis P. Founders' human capital and the performance of UK new technologybased firms. Small Business Economics, 2012, vol. 39, no. 2, pp. 495-515.

26. Huynh T. et. al. University spin-off's performance: Capabilities and networks of founding teams at creation phase. Journal of Business Research, 2017, vol. 78, pp. 10-22.

27. Patzelt H. CEO human capital, top management teams, and the acquisition of venture capital in new technology ventures: An empirical analysis. Journal of Engineering and Technology Management, 2010, vol. 27, no. 3-4, pp. 131-147. 
28. Protogerou A., Caloghirou Y., Vonortas N.S. Determinants of young firms' innovative performance: Empirical evidence from Europe. Research Policy, 2017, vol. 46, no. 7, pp. 1312-1326.

29. McGee J.E., Dowling M.J., Megginson W.L. Cooperative strategy and new venture performance: The role of business strategy and management experience. Strategic management journal, 1995, vol. 16, no. 7, pp. 565-580.

30. Brinckmann J., Hoegl M. Effects of initial teamwork capability and initial relational capability on the development of new technology-based firms. Strategic Entrepreneurship Journal, 2011, vol. 5, no. 1, pp. 37-57.

31. Zhao Y.L., Song M., Storm G.L. Founding team capabilities and new venture performance: The mediating role of strategic positional advantages. Entrepreneurship Theory and Practice, 2013, vol. 37, no. 4, pp. 789-814.

32. De Cleyn S.H., Braet J., Klofsten M. How human capital interacts with the early development of academic spin-offs. International Entrepreneurship and Management Journal, 2015, vol. 11, no. 3, pp. 599-621.

33. Dahl M. S., Reichstein T. Are you experienced? Prior experience and the survival of new organizations. Industry and Innovation, 2007, vol. 14, no. 5, pp. 497-511.

\section{Сведения об авторе / About author}

Кадиров Никита Тимурович, аспирант, Школа экономики и менеджмента, Дальневосточный федеральный университет. 690091 Россия, г. Владивосток, ул. Суханова, д. 8.

E-mail: kadirov_nt@dvfu.ru

Nikita T. Kadirov, Postgraduate Student, School of Economics and Management, Far Eastern Federal University. 8 Suhanova str., Vladivostok, Russia 690091. E-mail: kadirov_nt@dvfu.ru 